\title{
Strategic Planning approach for Optimising Investment at WWTPs
}

\author{
J. Krampe and M. Leak
}

South Australian Water Corporation, 250 Victoria Square, Adelaide SA 5000, Australia (E-mail: joerg.krampe@sawater.com.au)

\begin{abstract}
From an asset management perspective there is an ongoing challenge to make strategic investment decisions which are based on maintaining asset serviceability, effluent quality requirements and providing for growth. Additionally, individual performance of treatment stages and changes in sewage flows and loads have to be considered to achieve an optimised outcome.

Typically, large scale capital projects are required to address the many challenges that face a WWTP. However, significant cost savings can be made if smaller optimisation projects are pursued to maximise the capacity of existing infrastructure and therefore defer high cost capital upgrades. To achieve this end, SA Water started a formal process to review the capacity of each process element of the Bolivar WWTP and found several opportunities to optimise current process performance. Based on these outcomes a future strategy document was developed that enables the next major plant upgrade to be deferred by 8-10 years. This paper summarises SA Water's approach to develop such a documentation to allow a strategic asset management, optimise its capital expenditure and achieve significant cost savings. It also highlights some of the projects that were identified during this process to improve the current treatment plant performance.
\end{abstract}

Keywords Process review, process optimisation, strategic planning, asset management

\section{INTRODUCTION}

The South Australian Water Corporation (SA Water) is a utility wholly owned by the Government of South Australia. SA Water provides water, recycled water and wastewater service to approximately 1.5 million people across South Australia. SA Water owned infrastructure includes:

- 29 water treatment plants,

- $26,277 \mathrm{~km}$ water mains,

- $8,638 \mathrm{~km}$ sewers,

- 25 wastewater treatment plants,

- water recycling plants.

Capital expenditure has been increasing in recent times and in 2009/2010 the total capital expenditure was $\$ 1.16$ billion due to major projects such as the new Adelaide desalination plant and interconnector pipeline, major reuse projects and several upgraded or new wastewater treatment plants. These projects put significant pressure on all capital projects that SA Water can deliver throughout the next few years. As a result, SA Water is endeavouring to optimise the operation of its wastewater treatment plants to extend their capabilities with minimum expenditure. Therefore it is crucial to assess the performance and capabilities of the existing wastewater treatment plants and develop strategies for the future development of these sites. This paper outlines the approach taken for Bolivar WWTP, which has since been applied to other WWTPs within SA Water.

\section{BOLIVAR WWTP TREATMENT PROCESS}

Bolivar WWTP (Figure 1) is the main WWTP in metropolitan Adelaide with a design capacity of about 1.2 Million PE based on an population equivalent for $\mathrm{BOD}_{5}$ of $60 \mathrm{~g} / \mathrm{PE} / \mathrm{a}\left(\mathrm{PE}_{\mathrm{BOD} 60}\right)$. The design annual average flow (AAF) for Bolivar WWTP is $165 \mathrm{ML} / \mathrm{d}$ with a design peak wet weather flow (PWWF) of $500 \mathrm{ML} / \mathrm{d}$. Currently the plant is loaded with about 995,000 PEВоD60. Approximately $20 \%$ of the total load is from industry discharges.

CIWA Publishing 2012. The definitive peer-reviewed and edited version of this article is published in Water Practice \& Technology, Volume 7, Issue 2, 2012, doi: 10.2166/wpt.2012.030 and is available at www.iwapublishing.com. This is the accepted version. 


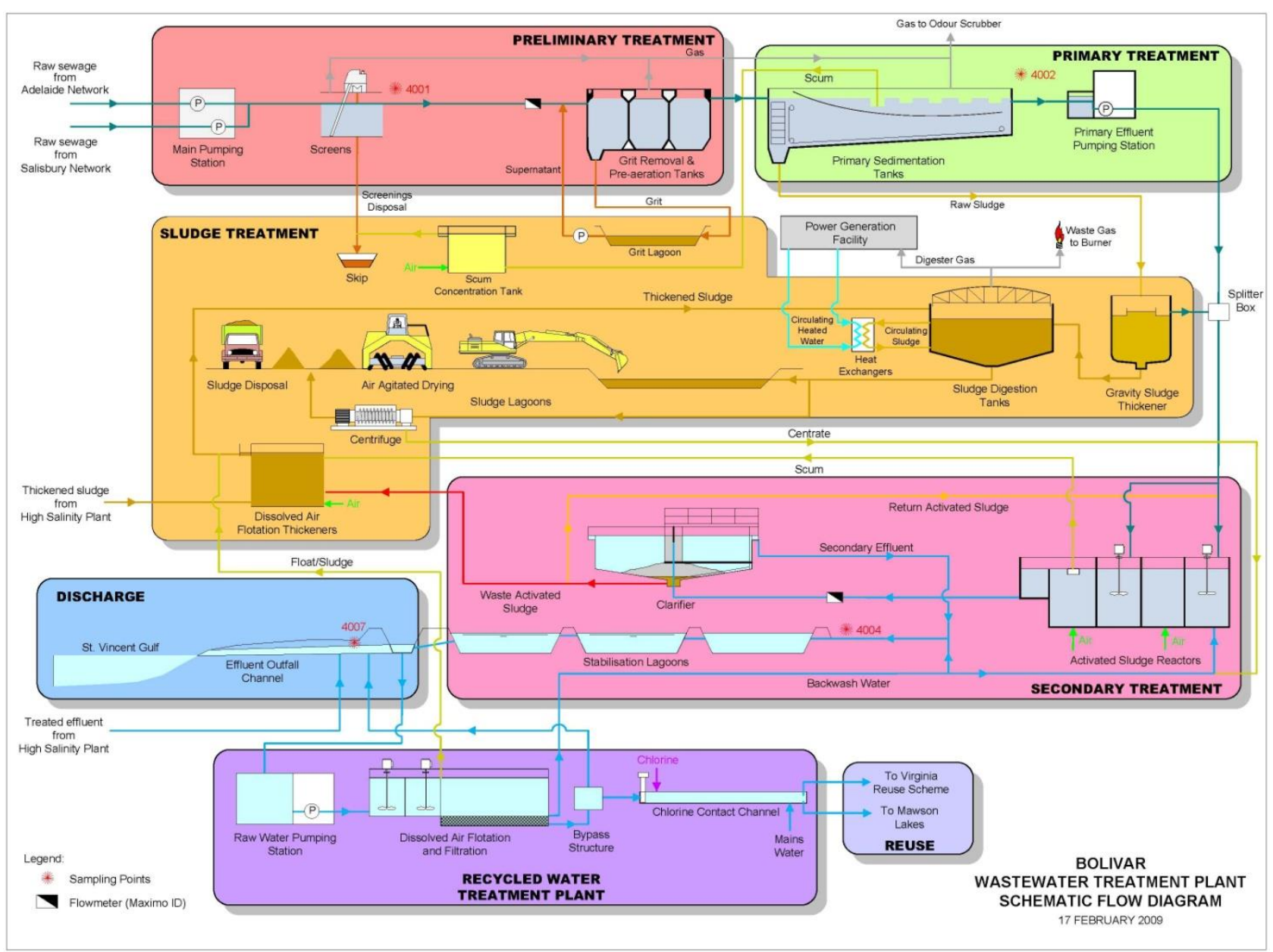

Figure 1: $\quad$ Schematic flow diagram for Bolivar WWTP

The wastewater process stream comprises a main pumping station, with screens and grit removal as the preliminary treatment. This step is followed by primary sedimentation tanks and a primary effluent pumping station.

The secondary treatment takes place in four activated sludge reactors combined with eight secondary clarifiers. Each train contains a small selector zone, two pre-denitrification and two nitrification zones. The reactors are built as step feed reactors with two stages. The design criteria and effluent targets for the activated sludge plant are summarised in Table 1 . The effluent of the secondary clarifiers flows into stabilisation lagoons with about 20 days detention time. Up to $65 \%$ of the effluent stream is further treated in a dissolved air flotation filtration tertiary plant (DAFF). This effluent stream is reused in the Virginia reuse scheme and in the Mawson Lakes dual reticulation scheme, with the remainder being discharged to the Gulf of St Vincent marine environment via an outfall channel.

Table 1: $\quad$ Design criteria and effluent targets for the activated sludge plant

\begin{tabular}{|c|c|c|c|c|}
\hline $\begin{array}{c}\text { BOD5 } \\
\text { in } \mathrm{mg} / \mathrm{L}\end{array}$ & $\begin{array}{c}S S \\
\text { in } \mathbf{m g} / \mathrm{L}\end{array}$ & $\begin{array}{c}\mathrm{TN} \\
\text { in } \mathrm{mg} / \mathrm{L}\end{array}$ & $\begin{array}{c}\mathrm{NH}_{4-\mathrm{N}} \\
\text { in } \mathrm{mg} / \mathrm{L}\end{array}$ & 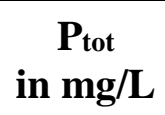 \\
\hline 20 & 20 & 24 & 5 & - \\
\hline
\end{tabular}

CIWA Publishing 2012. The definitive peer-reviewed and edited version of this article is published in Water Practice \& Technology, Volume 7, Issue 2, 2012, doi: 10.2166/wpt.2012.030 and is available at www.iwapublishing.com. This is the accepted version. 
The primary sludge is thickened by gravity sludge thickeners. The waste activated sludge is thickened in dissolved air flotation thickeners (DAFT) with the sludge from the DAFF plant. The whole thickened sludge is then digested in six mesophilic anaerobic digesters. The gas produced is used in a power generation plant to produce electricity and heat.

The digested sludge is divided into two trains. Part of the sludge is air dried in sludge lagoons and the rest is dewatered with two centrifuges. The dewatered sludge is dried by air agitated drying and all sludge is stockpiled for a period of 3 years before being disposed off-site as fertiliser in agriculture.

The plant was originally constructued in the 1960's and incorporated trickling filters for secondary treatment. The plant was upgraded in 2002 to reduce nitrogen levels discharged to the marine environment and to minimise odour emissions. The main change was the construction of BNR aeration reactors which replaced the trickling filters. The 8 original $30 \mathrm{~m}$ diameter humus tank clarifiers were utilised as secondary clarifiers for the new BNR process.

In Figure 2 the old trickling filters are still noticeable. The top end of the picture shows the stabilisation lagoons. The sludge handling areas for the digested sludge are not shown in the picture.

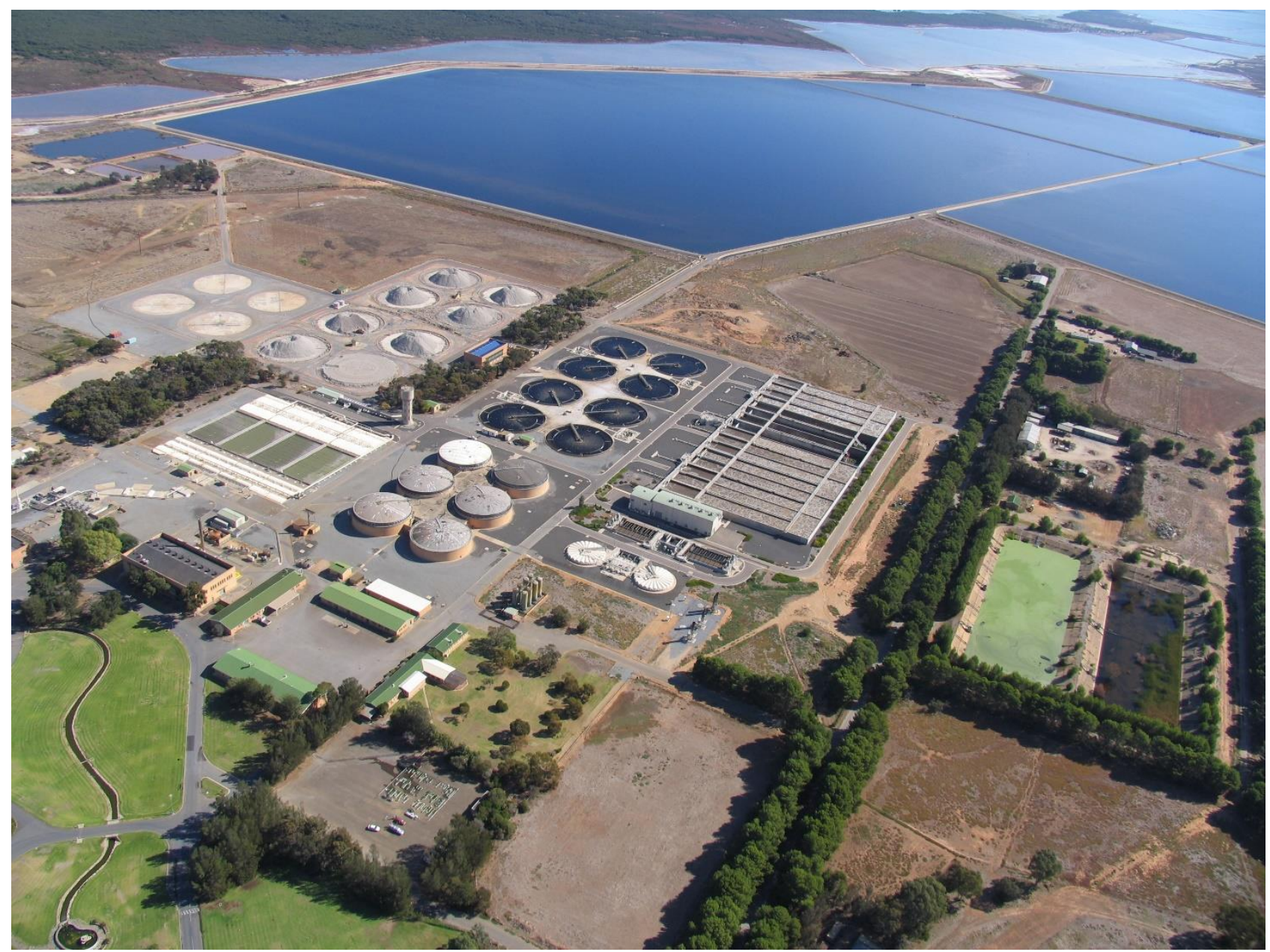

Figure 2: $\quad$ Aerial photograph of Bolivar WWTP not showing the sludge lagoons, hardstand and stockpiling area 


\section{STRATEGIC PLANNING APPROACH}

To optimise future investment decisions for the Bolivar WWTP, SA Water undertook a 2 stage approach, firstly doing a process review followed by the development of a future strategy plan. The objective of the process review was to determine the current flows and loads, to compare them to design numbers to establish the available capacity reserves of each process element, and to identify process optimisation projects to address process bottlenecks. The objective of the future strategy plan was to review the optmisation projects identified in the process review within the context of ensuring that the WWTP can adequately cater for future growth and also achieve other strategic objectives.

\section{Stage 1: Process review}

The initial step of the process review was to determine the current loads and flows on an annual basis for the last five years. This approach allowed tracking changes in the wastewater composition over the considered period. This was important as South Australia has been affected by drought over the last years which resulted in significant changes in the flows and sewage concentrations due to ongoing water restrictions. The data was then compared with the main relevant design parameters. Table 2 shows such a comparison of actual and design loads for the raw sewage. Similar comparisons were done for all main sampling points such as primary effluent, secondary effluent, digester inflows and the dewatering process.

Table 2: $\quad$ Comparison of actual loads and design loads for the raw wastewater based on median values

\begin{tabular}{lcccc}
\hline & $\begin{array}{c}\text { At time of up- } \\
\text { grades }\end{array}$ & Current* & Design & $\begin{array}{c}\text { Capacity } \\
\text { reserve }\end{array}$ \\
\hline AAF in ML/d & 130 & 147 & 165 & $11 \%$ \\
COD in kg/d & 168,750 & 122,695 & 206,250 & $40 \%$ \\
BOD5 in kg/d & 60,750 & 60,087 & 74,250 & $19 \%$ \\
Ptot in kg/d $_{\text {TKN in } \mathbf{~ k g / d ~}}^{2,025}$ & 1,704 & 2,475 & $31 \%$ \\
SS in kg/d & 10,800 & 9,898 & 13,200 & $25 \%$ \\
\hline
\end{tabular}

* Average of years between 2004 and 2009

Table 2 shows that there is sufficient spare capacity for most of the parameters considered. However, the capacity is not balanced as there is limited hydraulic capacity (11\%) and an unusually high spare capacity for suspended solids $(45 \%)$. The limited hydraulic capacity is a result of the secondary clarifiers. These were not upgraded when the aeration tanks were built in 2002 and are still the original humus tanks from the old Bolivar trickling filter plant. This is clearly a bottleneck of the current plant that needs to be addressed and will be discussed as part of the optimisation projects. The spare capacity in regard to the suspended solids is mainly a result of ongoing efforts of SA Water's Trade Waste group. Several industries were required to install on site pre-treatment stages and this reduced load clearly offers opportunities for process optimisation.

At the same time, the effluent quality was compared against design targets of the activated sludge stage. The activated sludge plant is achieving all targets apart from a few peaks which can be related back to solids carry over as a result of the secondary clarifiers as discussed above. These peaks do not have an effect on the overall effluent quality as the effluent lagoons polish the effluent. A high level energy benchmarking was also carried out (Table 3).

CIWA Publishing 2012. The definitive peer-reviewed and edited version of this article is published in Water Practice \& Technology, Volume 7, Issue 2, 2012, doi: 10.2166/wpt.2012.030 and is available at www.iwapublishing.com. This is the accepted version. 
The high specific energy consumption is to some degree a result of parasitic energy to supply the gas turbine as well as issues with the aeration system. In order to control odours at Bolivar the foul air is extracted from the primary sedimentation tanks and feeds it into the blowers of the biological stage for treatment in the aeration tank. The $\mathrm{H}_{2} \mathrm{~S}$ concentration of the foul air seems to result in a rapid deterioration of the silicone membrane diffusers which only achieve a lifetime of about 2.5 years. This has been identified as optimisation potential and will be discussed later.

Table 3: $\quad$ High level energy benchmarking

\begin{tabular}{lrl}
\hline & Bolivar 2007/2008 & Target \\
\hline Total energy consumption & $36,909 \mathrm{MWh}$ & \\
Specific energy consumption & $37 \mathrm{kWh} /(\mathrm{PE} \mathrm{a})$ & $27 \mathrm{kWh} /(\mathrm{PE} \mathrm{a})^{2)}$
\end{tabular}

\section{Total power consumption air gen- eration plant \\ Specific energy consumption for aeration}

Total gas production

Power generated on digested gas

Gas wasted

Electric power production effi-

ciency

Onsite power production
17,936.2 MWh

$18 \mathrm{kWh} /(\mathrm{PE} \mathrm{a}) \quad 10 \mathrm{kWh} /(\mathrm{PE} \mathrm{a})^{2)}$

1) Calculated with $6.5 \mathrm{kWh} / \mathrm{m}^{3}$ energy content of the digested gas and the used gas for electricity generation

2) Baumann and Roth (2008)

The high amount of wasted gas and the low electrical power production efficiency is a result of the poor reliability of the power generation plant that is currently used at Bolivar. The power plant compromises one single 3.8 MW turbine with only a gas boiler for backup. This results in wasted gas due to limited gas storage capacity. Additionally the digesters are not producing enough biogas to operate the turbine at its optimum performance (28\% efficiency) resulting in the low production efficiency. Currently there is a project underway to replace the single turbine with three engines with much higher efficiency $(\sim 40 \%)$. It is expected that the degree of onsite electricity production from biogas will increase well above $50 \%$ as a result of this project.

The outcomes of the process review were circulated, presented and discussed in workshops. First optimisation projects were included in the capital plan and initiated.

\section{Stage 2: Future strategy plan}

Developing the future strategy plan was the second stage following the process review. This included forecasts of the growth in the serviced area and identified external drivers which are expected to influence future upgrades. The future strategy was developed as a standalone document on at a high strategic level.

As part of the future strategy the expected growth of the connected area of the Bolivar WWTP has been predicted and applied to the main design parameters. Exemplary this is shown in Figure 3 for the CIWA Publishing 2012. The definitive peer-reviewed and edited version of this article is published in Water Practice \& Technology, Volume 7, Issue 2, 2012, doi: 10.2166/wpt.2012.030 and is available at www.iwapublishing.com. This is the accepted version. 
SS and $\mathrm{BOD}_{5}$ load. Ideally a plant would have a consistent spare capacity for all parameters and through all stages of the process. Figure 3 clearly outlines the problem of changes in the sewage composition which leads to spare capacity for single parameters that might not be easy to utilise in the context of the whole wastewater treatment plant. This shows how important it is to take a strategic approach.

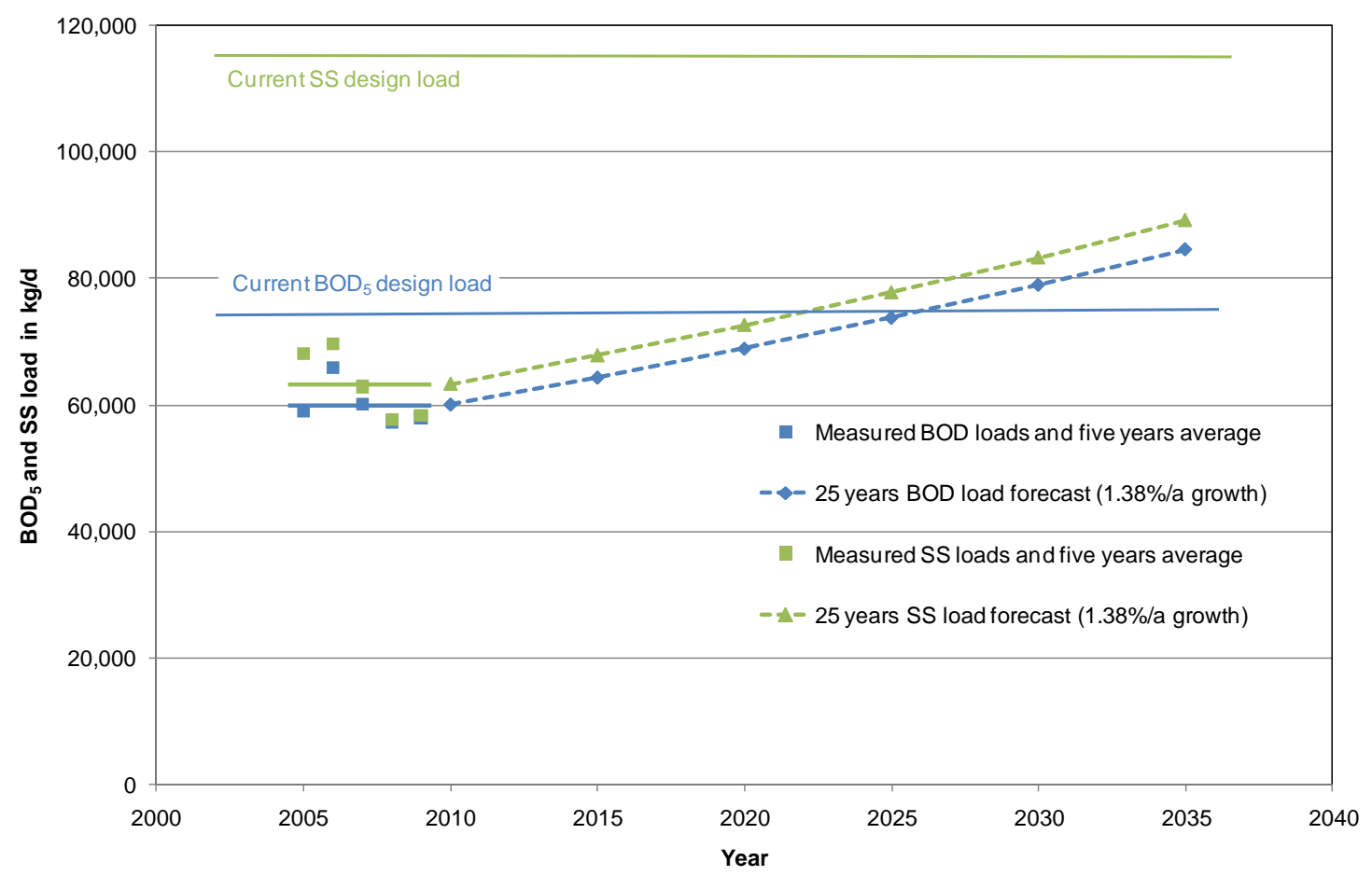

Figure 3: $\quad$ Growth forecast for Bolivar $\mathrm{BOD}_{5}$ and SS raw sewage loads based on the last five year average flows and $1.38 \%$ per annum growth rate

As the differences in the lifetime of different stages cannot be uniformly used, the main aim of the optimisation projects must be to align the capacity and achieve a consistent spare capacity for all relevant process parameters. For Bolivar it was decided to aim for a 2025 capacity which is aligned with the $\mathrm{BOD}_{5}$ load, is sooner than the SS load capacity and requires optimisation of the secondary clarifiers. At the same time the effluent quality needs to be optimised in order to minimise the load on the lagoons and minimise the discharge of nutrients, particularly nitrogen, to the marine environment. Therefore a strategy for Bolivar WWTP has been developed including optimisation projects to meet the flows and loads expected in 2025 and minimise redundancies for the future major capacity upgrade.

In addition, the following strategic issues have been identified that may impact on the future strategy and need to be considered in all relevant projects:

- Further nutrient reduction to reduce potential marine discharge impacts as required by the EPA

- Increasing reuse from the recycling plant

- Ongoing midge fly nuisance from the effluent lagoons affecting the local community

- Ongoing pressure to redevelop onsite buffer for residential use

- Maintaining salinity levels in the recycled water

- Greenhouse gas emission targets 
In a similar manner to the process review, the future strategy has been circulated, presented and discussed in workshops with different key stakeholders, some of whom were additional to the process review.

\section{Identified process optimisation projects}

Several projects have been recommended to address issues that arose as part of the process review and future strategy planning for direct implementation. As a result, the capital plan has been adjusted to defer the major capital upgrade project o at least 2025. Some key projects that are of specific interest are as follows:

Increased anoxic zones. The reduced suspended solids load in the sewage results in a reduced waste activated sludge (WAS) production compared to the design calculations. The lower WAS production can either be used to reduce the MLSS concentration in the aeration tanks or to increase the sludge age. As Bolivar WWTP has very small anoxic zones (the effluent lagoons are used for some further nitrogen removal) it was decided to increase the sludge age. The size of the anoxic zones has been increased by converting part of the aerobic zone to increase denitrification capability within the current tanks. The increased total sludge age allows keeping the aerobic sludge age constant while increasing the denitrification zones. The layout of a modified tank is shown in Figure 4.

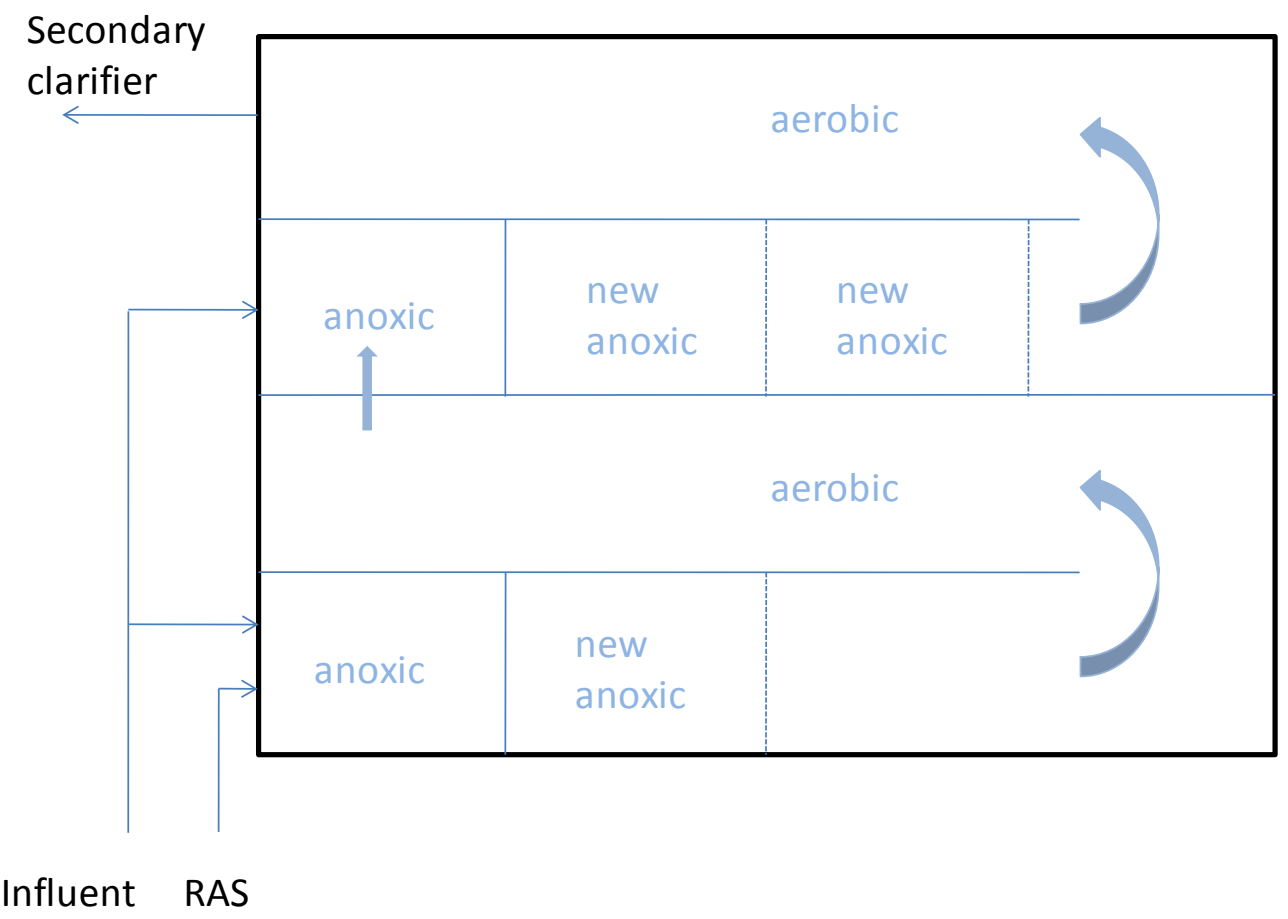

Figure 4: $\quad$ Modifications to the reactor layout showing the locations of the new anoxic zones

These modifications have been applied to one of four activated sludge reactors and the improvements are currently being monitored with online nitrate and ammonia sensors against a reference reactor. A review of the monitoring results over a range of flows, loads and seasonal changes in sewage characteristics will be undertaken to assess the impact of increased denitrification on effluent quality, it is expected that the other tanks will be modified similarly as the opportunities arise. Additionally benefits in regard to energy consumption and aeration efficiency (Rosso et al., 2008) are expected to be realised. 
Diffuser optimisation. As outlined above, the diffusers in the aeration tank receive foul air extracted from the primary sedimentation stage. The current diffusers are blade diffusers with a silicon membrane and achieve a limited lifetime of about 2.5 years only (compared with 5 years in a non foul air enviroment). As part of the review it was decided to setup a diffuser trial in one complete pass of one reactor to test disc diffusers with EPDM membranes. Because of the foul air present it was decided to test different slit sizes ( 1 and $2 \mathrm{~mm}$ ). Additionally some of the grids fitted with the new diffusers will be regularly cleaned with formic acid. Due to some specifics it is not possible to clean the current diffusers chemically. This project is setup as a trial to allow monitoring the backpressure of the diffusers in individual grids and will also allow off-gas testing over a period of three years in the trial and in a reference reactor. The trial is setup to provide a decision basis for future diffuser replacements. If the tested membranes do not achieve an improved performance over the current system, a separate foul air treatment stage might be considered instead of treating the foul air in the aeration tank.

Secondary clarifier capacity enhancement. As the current secondary clarifiers were designed as humus tanks for trickling filters they are not optimised for operation with activated sludge from an aeration tank. The sidewall depth is $3.15 \mathrm{~m}$ which is less than required to minimise solids carryover during high peak flows. However, the impact of solids carryover from the secondary clarifiers is low as effluent quality is polished in the stabilisation lagoons. Nevertheless, a significant sludge carry over has to be avoided. To improve the current situation and meet long term requirements, SA Water is currently collaborating with the University of Adelaide to develop a calibrated CFD model of the current clarifiers with the aim to design an improved inlet structure. As the current mechanical scrapers are showing signs of significant deterioration and imminent failure, the aim is to have a new design available once the replacement of the inlet structure and scraper mechanisms is required. Once one clarifier is equipped with a new inlet structure and scraper mechanism, a performance monitoring program will be used to validate the design and determine the peak hydraulic capacity which will then feed into the strategic plan for upgrading the remaining secondary clarifiers. It is expected that this action will defer the need to construct new high cost secondary clarifiers to increase the clarifier capacity to match the aeration tank capacity.

Other projects. Not only were capital projects identified during this process - changes were also applied to the operational focus of some stages (e.g. thickener performance vs. supernatant quality) or the sampling program with regards to process mass balances. Other optimisation projects that were identified during the review and related workshops include:

- Taking the pre-aeration tanks out of service

- Optimisation of primary sludge withdrawal to improve the primary sludge solid concentration

- Primary gravity thickener optimisation to improve the primary sludge solid concentration

- Modifications to the dissolved air flotation thickening stage (DAFT) to treat return streams from the sludge dewatering stage and the DAFF sludge and backwash water

- Better energy monitoring which includes additional sub metering and energy key performance indicators (KPIs)

\section{Research initiatives}

Apart from the above outlined technologies SA Water identified emerging technologies which might offer opportunities in future. Some of these technologies have not been applied throughout the corporation yet and some have not been applied in Australia. These technologies will be considered through SA Water's research and development process and it is expected that some technical scale and full scale trial projects will be developed with research partners in Adelaide. Such technologies are for example:

\section{- Supernatant/centrate treatment (Anammox or MAP processes)}

CIWA Publishing 2012. The definitive peer-reviewed and edited version of this article is published in Water Practice \& Technology, Volume 7, Issue 2, 2012, doi: 10.2166/wpt.2012.030 and is available at www.iwapublishing.com. This is the accepted version. 
- Sludge pre-treatment (WAS hydrolysis)

- Using organic rankine cycle (ORC) process to generate electricity from waste heat from gas engines

\section{SUMMARY AND CONCLUSIONS}

This paper demonstrates how a design review and future strategy document was developed for SA Water's largest WWTP. Such an approach allows key stakeholders such as asset management, operations, design, long term planning and environmental management to consolidate and align their individual requirements. Finally such an approach is targeted to allow a more accurate medium and long term capital plan.

In the way it was developed within SA Water, it also presents a process summary and reference document that allows project managers to see how their projects fit into the whole planning process and which strategic issues have to be considered and addressed in their project.

While most utilities will have key personnel that have the big picture in their minds, SA Water found it an important process to develop the strategy from first principles. This included a series of workshops that made it easier to involve key stakeholders.

It was decided to keep the documentation high level as such strategies need to be living documents that are reviewed and updated regularly. Based on the positive experience with this work, SA Water has since then continued the process for other WWTPs in South Australia.

\section{REFERENCES}

Baumann, P, Roth, M. (2008), Senkung des Stromverbrauchs auf Kläranlagen, Leitfaden für das Betriebspersonal, (Reduction of the energy consumption on WWTPs - Handbook for operators) Heft 4, DWA Landesverband Baden-Württemberg

Rosso, D., Larson, L.E., Stenstrom, M.K. (2008), Aeration of large-scale municipal wastewater treatment plants: state of the art, Water Sci. Technol. 57 (7), $973-978$ 